\title{
INVESTIGACIÓN-ACCIÓN: RESEÑA Y APORTES DEL TALLER DE CREATIVIDAD DEL CONSULTORIO PSICOLÓGICO DE LA UNIVERSIDAD NACIONAL MAYOR DE SAN MARCOS
}

\author{
INVESTIGATION ACTION OUTLINES AND CONTRIBUTION OF THE \\ WORKSHOP CREATIVITY DEVELOPED BY CONSULTORIO PSICOLÓGICO \\ (COPSI) OF UNIVERSIDAD NACIONAL MAYOR DE SAN MARCOS
}

\author{
Ricardo Oliveros M. ${ }^{1}$, Victor Urina R. $^{2}$, Tanya Martinez A. $^{2}$ \\ Universidad Nacional Mayor de San Marcos, Lima, Perú \\ (RECIBIDO EL 21/10/2009, ACEPTADO EL 12/12/2009)
}

\begin{abstract}
RESUMEN
Se realiza una primera evaluación del Taller de Creatividad del Consultorio Psicológico de la UNMSM, destacando las fortalezas presentes y las potencialidades futuras de la práctica de formación en creatividad personal, considerando sus aportes al desarrollo institucional y a la comunidad.
\end{abstract}

Palabras clave: Formación personal, creatividad, comunidad, desarrollo institucional.

\begin{abstract}
It carries out a first evaluation of the Creativity Workshop of the Psychological office of the UNMSM, highlighting the present fortresses and the future potentialities of training in personal creativity practice, considering its contributions to the institutional development and to the community.
\end{abstract}

Keywords: Personal training, creativity, community, institutional development.

\footnotetext{
1 Docente investigador del Instituto de Investigaciones Psicológicas de la Facultad de Psicología, Universidad Nacional Mayor de San Marcos, Lima-Perú. E-mail: roliverosm@unmsm.edu.pe

2 Psicológos del Consultorio Psicológico.
} 


\section{INTRODUCCIÓN}

Trabajamos con el firme propósito de mejorar la calidad de la educación y, desde nuestra actividad profesional, estamos elaborando una propuesta de desarrollo de la creatividad personal, porque deseamos contribuir en la formación integral de la personalidad de los niños del Perú. Nos interesa desarrollar estrategias para promover la creatividad personal de los participantes en el Taller de Creatividad del COPSI.

\section{La Unidad de Desarrollo de la Creatividad}

\section{Reseña histórica}

La Unidad de Desarrollo de la Creatividad del COPSI-UNMSM tiene su origen en el primer Taller de Creatividad y Literatura para niños programado y ejecutado en el COPSI en el verano del 2004 (enero-marzo) por V. Hugo Urbina Reyes y Tanya Martínez Aparicio, taller concebido para fomentar la práctica y comprensión de la lectura y promover la creación literaria.

Ese mismo año, entre los meses de agosto y diciembre, el taller fue ejecutado en el Centro Educativo 3512 de la comunidad rural de Chocas y en el local de la Asociación de Agricultores de la misma comunidad. Chocas pertenece al distrito de Carabayllo y se ubica en el kilómetro 34 de la carretera a Canta (Lima).

En el año 2005 se constituye el Programa de Desarrollo de la Creatividad y a partir de enero de ese año realiza actividades permanentes en el COPSI, ejecutando talleres de Creatividad y Literatura para niños y charlas para los padres de los niños participantes. Asimismo, durante el 2005, el Programa realizó actividades en la comunidad rural de Chocas. Desde finales del 2005 el programa cuenta con un espacio propio dentro de las instalaciones del COPSI.

En el 2006, además de continuar con sus actividades en el COPSI, el programa ejecutó el Taller de Creatividad y Literatura para niños en el AA. HH. Nueva Florida del distrito de Comas, en diferentes periodos de ese año. Asimismo realizó un nuevo Taller de Creatividad y Literatura para niños en el Centro Educativo 3512 de la comunidad rural de Chocas, entre los meses de agosto y noviembre.

En el 2007, el programa prosigue con sus actividades en el COPSI. Durante el verano de ese año nuevamente ejecutó el Taller de Creatividad y Literatura para niños en el Asentamiento Humano (población de extrema pobreza) Nueva Florida del distrito de Comas.

Desde el año 2008, el Programa se convierte en la Unidad de Desarrollo de la Creatividad (UDECREA), unidad especializada del COPSI que continuamente realiza talleres de Creatividad y Literatura para niños y charlas para los padres de los niños participantes. Asimismo, la UDECREA ha abierto otros servicios, como el Taller de Escritura, cuyo objetivo es promover el desarrollo de habilidades para la lectoescritura en niños que inician su escolaridad.

\section{Papel del Taller de Creatividad y Literatura}

Hay que destacar el papel del Taller de Creatividad y Literatura en la formación de la personalidad de niños y niñas, y de los y las adolescentes, a través del Programa de desarrollo 
de la creatividad y literatura, que es uno de los programas del Consultorio Psicológico. Tiene grandes perspectivas: como psicopedagogía sociocultural, para el desarrollo de la personalidad; y, como psicopedagogía clínica, para la superación de bloqueos de la personalidad o dificultades de aprendizaje personal creativo.

Se trata de una tarea realmente excepcional, con pocos recursos realizan una labor de orientación del desarrollo personal y favorecen el desarrollo de capacidades personales con actividades y tareas que impulsan la libre expresión de la creatividad personal.

Ahora bien, ¿cómo es el Taller de creatividad y literatura del COPSI? Se trata de un ambiente sencillo que une concreta y prácticamente las conductas reales de los niños con las maravillosas posibilidades de la imaginación constructiva, de la creatividad en acción. Los participantes del Taller de creatividad y literatura descubren la alegría de aprender, la alegría de vivir y de amar.

La alegría de aprender, porque estudian bastante para todo lo que realizan en el taller, leen cuentos y poesías y, también escriben cuentos y poesías, además de comunicarse un sinfín de relatos aleccionadores para orientar la vida personal. No hay notas, no hay presión negativa. Hay aprendizajes que fluyen significativamente para la libre expresión de las capacidades personales, como manifestación del desarrollo creador de las potencialidades humanas.

La alegría de vivir, porque de manera práctica viven la experiencia de crear, la alegría de ser personas creativas, la alegría de poner su propia creatividad personal al servicio de una vida buena. Sí, creatividad personal para vivir mejor, visualizando nuevos estilos de vida personal. Creatividad personal para diseñar los sueños personales hacia lo mejor. Creatividad personal para utilizar constructivamente los propios recursos personales.

La alegría de amar, los participantes del Taller de creatividad y literatura sienten un clima positivo y constructivo de formación personal. Se sienten aceptados y sienten que crecen como personas, crecen en autoconfianza personal, crecen en seguridad en el uso de sus capacidades personales, crecen en el placer de ser creativos y en ser constructivos de una manera compartida, con amigos y entre amigos.

\section{ENFOQUE TEÓRICO}

\section{Papel de la creatividad personal}

Se trata de la creación de una situación de aprendizajes creativos puestos al servicio del desarrollo personal (como proceso de desarrollo de capacidades personales) y, en no pocas ocasiones, funcionales a la tarea de crecimiento personal (entendida como el proceso de superación de los bloqueos personales). Una puesta en funcionamiento de diversas situaciones de aprendizaje que promueven la libre expresión de la creatividad personal, como proceso de convertirse en mejores personas, en personas educadas.

Comprendiendo la "creatividad personal" como una configuración psicológica especial que opera tanto en la tarea personal de diseño del estilo de vida que uno quiere tener, como en el trabajo personal de gestión de las capacidades personales para el logro de los objetivos y metas personales". 


\section{Crecimiento personal y desarrollo personal}

Consideramos el desarrollo personal como aprendizaje y gestión de recursos personales. La creatividad personal como competencia personal integradora de la dinámica de formación de niños y adolescentes. La "creatividad personal" operando tanto en los procesos de socialización como en los procesos de personalización (Chivas Ortiz, 2001, 2002; García Ramis, 2004; Lowenfeld, 1961; Mitjáns Martinez, 1999).

- Papel de la "creatividad personal" en el desarrollo personal. En función al aprendizaje de nuevas capacidades personales y a la gestión de las capacidades personales en función al desarrollo personal.

- Papel de la "creatividad personal" en el crecimiento personal. Desaprendizaje de los bloqueos personales y gestión de las capacidades personales en función a la superación de los bloqueos personales.

La "creatividad personal" como eje de la autodinámica constructiva de la personalidad y de la actuación de la personalidad. La dinámica de formación integral de la personalidad como proceso de articulación de capacidades personales y como puesta en funcionamiento de capacidades personales. (Csikszentmihalyi, 1998; Kubie, 1966).

\section{La "creatividad personal" y la formación de la personalidad}

Comprendiendo la "creatividad personal" como una configuración psicológica especial que opera tanto en la tarea personal de diseño del estilo de vida que uno quiere tener, como en el trabajo personal de gestión de las capacidades personales para el logro de los objetivos y metas personales.

En tal sentido, como dispositivo generador, la "creatividad personal" funciona todos los días y debe enmarcarse en una visión de futuro personal. Aquí, precisamente, las actividades y tareas relacionadas con el desarrollo de la creatividad cumplen un papel extraordinariamente importantes. Al respecto, es bueno tener presente lo siguiente:

La creatividad es de todos los días, desde que nos levantamos hasta que nos acostamos, cómo enfrentamos el día, la vida; cada suceso, cada acontecer requiere su cuota, en mayor o menor grado.

La creatividad es un suceder, podemos imaginar una forma para definirla, por ejemplo la imagen de una espiral que gira, gira y gira en un sin fin de vueltas, y en cada vuelta en espiral ascendente esta sube con una nueva motivación, con un nuevo conocimiento, experiencia, deseo, arremolinando hacia arriba o hacia abajo, las direcciones pueden ser múltiples y diversas, no importa la dirección que adopte; importa el sentido y el significado que se encuentra en este ir.

Una espiral siempre trasciende su movimiento, nunca retorna atrás. Si hacemos una analogía entre la espiral y la creatividad, podemos decir que en ambas se engendra la fuerza, se dan los flujos de energía, son saltos vitales, hacen a la integración universal, a la búsqueda de la perfección, al dinamismo. Nosotros nos sumergimos en el proceso creador como en movimiento de espiral, avanzando con cada idea, con cada acción, con cada movimiento, con cada elaboración y producción. 
Luchamos por conquistar la creatividad, en esa lucha nos transformamos a nosotros mismos y transformamos el medio ambiente (físico y social)".

\section{El desarrollo personal y los bloqueos de la personalidad}

Lo más significativo que pone en acción el Taller de Creatividad y Literatura del COPSI es la promoción del desarrollo personal y la superación de los bloqueos de la personalidad. Para una mejor comprensión de lo señalado, es importante destacar, del Diccionario de creatividad, las dos acepciones, así se puede comprender la importancia estratégica del desarrollo de la creatividad y la formación de personas creativas:

\section{Desarrollo personal}

La relación de una persona consigo misma en la óptica educativa puede denominarse desarrollo personal. La creatividad se relaciona con la tecnología y el mundo del trabajo, pero ante todo se relaciona con las personas y las posibilidades que éstas tienen de actualizar sus potencialidades. Carl Rogers, el psicólogo humanista, ha insistido en destacar el factor de implicación personal en el acto creativo, señalando que debemos enfrentar el hecho de que el individuo crea sobre todo porque eso lo satisface, y porque lo siente como una conducta autorrealizadora.

La creatividad apunta al cambio, a conseguir algo que antes no teníamos o no conocíamos. El cambio es una categoría del proceso creativo que impacta en el ambiente y afecta a las personas. La conducta creativa implica transformaciones sistemáticas en las personas que deberían traducirse positivamente en su forma de pensar, sentir y de interactuar. La exigencia de originalidad tiene una intima relación con el desarrollo personal. Esta sólo surge cuando la persona interactúa con otras personas y los materiales y circunstancias de su entorno desde su condición de ser único. Por tanto, ésta es posible sólo cuando una persona se decide a expresar lo que tiene de propio e irrepetible. Por otra parte, la noción de relevancia que se funde con la de originalidad, para dar lugar a un resultado creativo, es aquello que tiene valor para una persona en un contexto y tiempo específicos, de acuerdo a requerimientos determinados. Esto significa que lo relevante no es algo objetivo y puede variar de una persona a otra. No existe una relación necesaria entre hecho y valor. Decidir que algo es relevante, es optar, despejar una duda, escoger una alternativa, y ello pone en juego necesariamente una definición de sí mismo. En una palabra, se requiere un sentido de identidad personal y éste es uno de los fundamentos de todo desarrollo personal.

\section{Bloqueos de la personalidad}

Todos los seres humanos son creativos en algún grado. En la actualidad se reconoce que la creatividad no está restringida únicamente a seres excepcionales, y se encuentra como un potencial en cada persona sin excepción. Es un hecho, sin embargo, que la expresión de la creatividad no siempre ocurre de manera expedita, y con frecuencia se encuentra con obstáculos que no consigue superar. Se puede hablar de resistencias, bloqueos, barreras, amarras o inercias (ver), lo concreto es que con todas esas expresiones se busca señalar la existencia de algún factor que se interpone para 
impedir la conducta creativa. Los bloqueos pueden frenar la creatividad en forma total o parcial, durante períodos de tiempo muy largos, en toda situación o sólo en alguna de ellas, de modo que una tarea propia de la estimulación de la creatividad consiste en identificarlos y buscar fórmulas para impedir su presencia. Estos básicamente pueden estar en la persona, actuando tanto en el plano intelectual como afectivo, o en su ambiente, actuando en los grupos y en la cultura en forma de influencias restrictivas.

El siguiente es un listado que incluye distintos tipos de bloqueos:

- Temor al fracaso, que hace retroceder y rechazar los riesgos.

- Resistencia a jugar, que genera personas sin humor y apegadas a lo conocido.

- Tendencia a la rutina, que anula la posibilidad de descubrir oportunidades.

- Miedo a lo desconocido, que cierra el camino de las nuevas experiencias.

- Exceso de certeza, que perpetúa una sola línea de pensamiento y de acción.

- Excesiva rigidez, que no permite valorar y utilizar tanto la lógica como la fantasía.

- Desaprovechamiento de los sentidos, que empobrece la experiencia.

- Emocionalidad temerosa, que paraliza frente al poder de los afectos.

- Falta de sentido crítico, que predispone a la obediencia y al conformismo.

- Rechazo a la diferencia, que oscurece la visión de nuevas ideas.

- Falta de proyectos compartidos, que impide formas activas de colaboración.

- Ausencia de autoconocimiento, que entorpece el desarrollo del propio potencial.

\section{MÉTODO}

\section{Reflexión teórico-constructiva y enfoque de investigación-acción en creatividad}

El método utilizado es de síntesis teórica en la modalidad de reflexión teórico-constructiva y un enfoque de investigación-acción en creatividad en la modalidad de sistematización de una práctica de formación.

Se trata de una primera aproximación para mejorar la calidad del servicio que se brinda, para mejorar el perfil de los voluntarios, para mejorar la participación de las madres y padres de familia, y para mejorar la actuación personal de los participantes en el Taller de Creatividad. 


\section{RESULTADOS}

\section{Sistematización de una práctica de formación y producción de conocimiento orientador en creatividad}

En la realización del Taller de Creatividad del COPSI surgen muchas preguntas y en el equipo responsable también nos hacemos preguntas. Se trata de preguntas relacionadas con las diversas actividades para desarrollar las capacidades creativas de los participantes en el Taller de Creatividad. Nos preguntamos, por ejemplo: ¿Cuáles son las desventajas que genera el agostamiento psíquico y qué se puede hacer desde la familia y la escuela para lograr el desarrollo psicológico de niñas y niños? ¿Cuáles son las limitaciones que produce el apocamiento personal? ¿Cuáles son los climas familiares y escolares que generan agostamiento psíquico y apocamiento personal? ¿Cómo se relaciona la imaginación creadora con la superación de las dificultades de aprendizaje? ¿Cómo se relaciona la imaginación creadora con la solución de los problemas de desarrollo personal? ¿Qué entendemos por imaginación creadora? ¿Cómo se fomenta la imaginación creadora en el Taller de Creatividad del COPSI? ¿Por qué trabajamos en psicopedagogía de la creatividad en el Taller de Creatividad COPSI? Y muchas preguntas más.

Son preguntas que nos invitan a mejorar nuestra propuesta de desarrollo de la creatividad, preguntas que nos llevan a reflexionar para innovar las actividades que organizamos para los participantes. Queremos contribuir con lo mejor de nuestros aportes profesionales y lo hacemos con todo nuestro corazón, asumiendo con responsabilidad la tarea de formar mejores personas promoviendo la creatividad personal. Y nos guía el deseo de superar todo lo que limita la libre expresión de la creatividad personal de los participantes. Por lo tanto, siempre realizamos reflexiones conjuntas, todo el equipo responsable de la realización del Taller de creatividad del COPSI.

\section{¿Qué pasa con los aprendizajes de los participantes en el Taller de Creatividad y Literatura del COPSI?}

Los aprendizajes personales de los participantes en el Taller de Creatividad y Literatura del COPSI se ven positiva y constructivamente incrementados, pero también son mejores aprendizajes personales para favorecer la libre expresión de las capacidades personales y para la superación de los bloqueos en el desarrollo de la personalidad.

En primer lugar, se trata verdaderamente de aprendizajes significativos porque orientan, y en no pocos casos reorientan, la experiencia existencial de los participantes. Muchos de los participantes vienen con percepciones limitadas acerca de sus propias posibilidades de desarrollo personal. En tal sentido, la tarea principal del Taller de Creatividad y Literatura del COPSI consiste en desarrollar la confianza en las capacidades y en generar una perspectiva positiva en cada uno de los participantes.

En segundo lugar, de una manera profunda y estratégica, se trata de aprendizajes significativos porque estructuran dinámicamente, y en no pocos casos reestructura configuraciones negativas, la actividad personal de los participantes en el Taller de Creatividad y Literatura del COPSI. Todos los participantes desarrollan una nueva 
percepción de su propia vida personal, percepción que es compartida por sus padres y madres. Se nota la emergencia de una nueva forma de ver los aprendizajes, aprender a creer para crear, aprender a crear para crecer; en suma, se trata de aprender a ser feliz a través del ejercicio libre de la creatividad personal.

Al respecto, lo destacamos de manera especial, nuestros participantes en el Taller de Creatividad nos hacen muchas preguntas porque son niñas y niños deseosos de crear, expresando su alegría de aprender cuando el clima de aprendizaje es creativo y motivador. Y tenemos la satisfacción de atender a las preguntas de las madres y padres de familia de los participantes, realmente interesados en la formación integral de sus hijas e hijos. Se trata de preguntas que nos exigen profundizar en nuestra propuesta de psicopedagogía de la creatividad y en la importancia de realizar innovaciones permanentes en nuestra práctica de formación en creatividad.

¿Qué pasa con los voluntarios de la Facultad de Psicología que integran el equipo del Taller de Creatividad del COPSI?

Los estudiantes de la Facultad de Psicología de la UNMSM tienen la extraordinaria oportunidad de aprender psicología de la creatividad en un ambiente de formación y desarrollo de la creatividad. Esto es realmente significativo porque contribuye a su formación en psicología humana con seres humanos, un aspecto que debe ser destacado y apoyado, sobre todo si se piensa en una renovación profunda de la formación de los psicólogos en el siglo XXI. Puede parecer una redundancia, pero es importante destacarlo, educa su paciencia y su tolerancia, desarrolla su imaginación psicológica para la comprensión de diversidad de conductas personales y para la orientación psicopedagógica de las potencialidades de los participantes en el Taller de Creatividad del COPSI.

\section{¿Cuáles son las desventajas que genera el agostamiento psíquico y qué se puede hacer desde la familia y la escuela para lograr el desarrollo psicológico de niñas y niños?}

Agostamiento psíquico $=$ empobrecimiento de la conciencia, incluso en situaciones extremas se puede hablar de envilecimiento de la conciencia.

Las limitaciones que genera el agostamiento psíquico son muchas. En no pocas ocasiones, lamentablemente, al ser considerado tonto el niño comienza a ser blanco de burlas y de rechazos, limitando su desarrollo personal a lo más elemental, conformándose con aprender poco y mal porque al sentirse tonto disminuye sus aspiraciones.

La familia y la escuela deben de contribuir al desarrollo de la niña y el niño sin prejuicios y ampliando el desarrollo de sus capacidades personales.

Sugerencia: leer y reflexionar -de manera especial- el texto: Nadie puede maltratarte por no aprender rápido, para poder orientar a las niñas y niños.

\section{¿Cuáles son las limitaciones que produce el apocamiento personal?}

Apocamiento personal $=$ bloqueos personales, inseguridad personal, limitaciones y deformaciones del desarrollo personal. 
Las limitaciones que produce el apocamiento personal son muchas. Estamos ante casos de maltrato infantil que genera bloqueos personales (miedos, ansiedades, inseguridades, etc.). Es muy importante crear un clima familiar y escolar favorable a la superación de los bloqueos personales, con estrategias de crecimiento personal mediante estrategias de desarrollo de la creatividad personal bloqueada, reprimida, inutilizada. Los niños apocados tienen baja autoestima, no participan en actividades, se separan de sus compañeros, sufren solos, son sumamente inseguros con relación al desarrollo de sus capacidades personales.

\section{¿Cuáles son los climas familiares y escolares que generan agostamiento psíquico y apocamiento personal?}

Los climas familiares que generan agostamiento psíquico y apocamiento personal son las familias con conflictos que no se manejan bien, familias que no encuentran maneras adecuadas para resolver sus problemas, familias donde hay poca comunicación y sobre temas sin importancia real, etc. Igualmente, los climas escolares autoritarios limitan las posibilidades de libre expresión de la creatividad personal de los estudiantes. Escuelas que no organizan la participación de los estudiantes, que no facilitan el desarrollo de la creatividad personal de los estudiantes con actividades motivadoras y que promueven el esfuerzo orientado en los estudiantes.

\section{¿Qué entendemos por imaginación creadora? ¿Cómo se fomenta la imaginación creadora en el Taller de Creatividad del COPSI?}

Se trata de una actividad personal especial que se manifiesta en el sistema de la actividad personal responsable del desarrollo personal. Una actividad especial que, para cualquier persona concreta, consiste en generar un "resultado, no es la reproducción de impresiones o acciones que formaron parte de su experiencia", sino que consiste en generar "la creación de nuevas imágenes o acciones".

La imaginación creadora puede desarrollarse con la promoción de la creatividad personal y con actividades organizadas para desarrollar los recursos creativos de las personas.

Mediante la planificación y realización de diversas actividades que promueven el desarrollo de la creatividad personal: lectura creativa, escritura de poemas y de cuentos, elaboración de títeres, práctica del teatro, etc.

\section{¿Cómo se relaciona la imaginación creadora con la superación de las dificultades de aprendizaje? ¿Cómo se relaciona la imaginación creadora con la solución de los problemas de desarrollo personal?}

Consideramos que el agostamiento psíquico y el apocamiento personal son cuestiones que se relacionan con dificultades de aprendizaje y problemas de desarrollo personal. Por lo tanto, tenemos la convicción de que la promoción de la actividad creadora contribuye a 
la superación tanto de las dificultades de aprendizaje como a la solución de los problemas de desarrollo personal. La imaginación creadora desarrolla estrategias para superar los bloqueos personales y genera condiciones favorables a la libre expresión de las capacidades personales.

\section{¿Por qué trabajamos en psicopedagogía de la creatividad en el Taller de Creatividad del COPSI?}

Porque confiamos en el futuro del país, porque tenemos la convicción que la promoción de la imaginación creadora y el desarrollo de la creatividad personal generan condiciones favorables al desarrollo de todos. Porque queremos enriquecer nuestra propuesta de psicopedagogía de la creatividad. Porque amamos a las niñas y a los niños y porque deseamos lo mejor para ellos que son el presente y el futuro del Perú.

\section{DISCUSIÓN}

\section{¿Por qué psicopedagogía clínica en el Taller de Creatividad y Literatura del COPSI?}

Porque el Taller de Creatividad y Literatura genera no solamente un desarrollo ampliado de las capacidades personales de los participantes (cuestión clave en los modelos de desarrollo personal, con orientación psicopedagógica), sino que también genera condiciones para un proceso de superación de bloqueos personales (aspecto principal de los modelos de crecimiento personal, con orientación psicológica).

Así, de acuerdo a lo señalado, el aprendizaje de recursos personales para prevenir y superar bloqueos personales contribuye a la reflexión de cuestiones de psicopedagogía clínica. En tal sentido, afirmamos que no se trata de que los participantes se curen "milagrosamente", sino que es el clima desarrollador de aprendizajes creativos lo que genera tanto el crecimiento personal como el desarrollo personal de los participantes.

Los participantes, y también sus padres, aprenden las bondades de la libre expresión de las capacidades personales y las ventajas formativas de la superación de los bloqueos personales. Se trata de la puesta en práctica de un proyecto emancipador de las capacidades personales, en una dinámica de re-creación y de innovación del pensamiento psicológico humanista.

\section{CONCLUSIONES}

Para seguir avanzando en la reflexión

1. En el Taller de Creatividad y Literatura del COPSI, la dinámica formativa de la creatividad personal se expresa de la siguiente manera:

- Con relación a los participantes, el Taller de Creatividad y Literatura aporta elementos que promueven la expresión de la "creatividad personal", que desarrollan la alegría de vivir y aprender. Una perspectiva emancipatoria en el aprendizaje de la libertad. 
- Con relación a las madres y padres de los participantes, el Taller de Creatividad y Literatura aporta elementos que promueven mejoras en la dinámica familiar. Una perspectiva renovadora de las relaciones familiares, destacando el papel de la "creatividad personal" y de la cultura familiar en la relación de pareja y en la educación de los hijos.

- Con relación a los voluntarios del Taller de Creatividad y Literatura, se debe profundizar en las posibilidades formativas para los futuros psicólogos, especialmente para los que se orientan hacia la psicología clínica y educativa. Da vértigo imaginar la cantidad de trabajos reales que podrían hacer los estudiantes de la Facultad de Psicología en el Programa de Desarrollo de la Creatividad del COPSI.

2. Sobre la base de los productos (textos elaborados y publicados) que genera el Taller de Creatividad y Literatura, es importante seguir avanzando en la reflexión sobre la importancia de las cuestiones de psicopedagogía clínica para la formación de personas educadas en el siglo XXI.

3. Se trata de un valioso aporte significativo de la Facultad de Psicología de la UNMSM a la renovación de los modelos de formación humana para renovar el proceso educativo. Se dan orientaciones prácticas para mejorar la cultura escolar, para descubrir la alegría de ser creativo y la alegría de aprender a ver la vida con una nueva perspectiva.

\section{NOTAS}

1 http://www.intangiblecapital.org/Articulos/N2/0024.htm

2 http://www.udp.cl/comunicacion/magcom/docs/diccionario.pdf

3 Documento de trabajo del UDECREA del COPSI.

4 Carl Rogers (1975). Aprendiendo a ser libre. En Rogers, Carl y Stevens, Barry. Persona a persona, Amorrortu editores.

\section{REFERENCIAS BIBLIOGRÁFICAS}

1. Csikszentmihalyi, Mihaly (1998). Creatividad. El fluir y la psicología del descubrimiento y la invención. Barcelona: Editorial Paidós.

2. Chivas Ortiz, Felipe (2001). Creatividad y cultura. Cuba: Editorial Pueblo y Educación.

3. Chivas Ortiz, Felipe (2002). Creatividad. Cultura. Cuba: Eurekas. Editorial Pueblo y Educación.

4. García Ramis, Lisardo (Selección, 2004). La creatividad en la educación. Cuba: Editorial Pueblo y Educación,

5. Kubie, Lawrence (1966). El proceso creativo, su distorsión neurótica. México: Editorial Pax.

6. Lowenfeld, Viktor (1961). Desarrollo de la capacidad creadora. Buenos Aires: Editorial Kapeluz.

7. Mitjáns Martinez, Albertina (1999). Creatividad, personalidad y educación. Cuba: Editorial Pueblo y Educación. 
Investigación-acción: Reseña y aportes del Taller de Creatividad del Consultorio Psicológico de la UNMSM

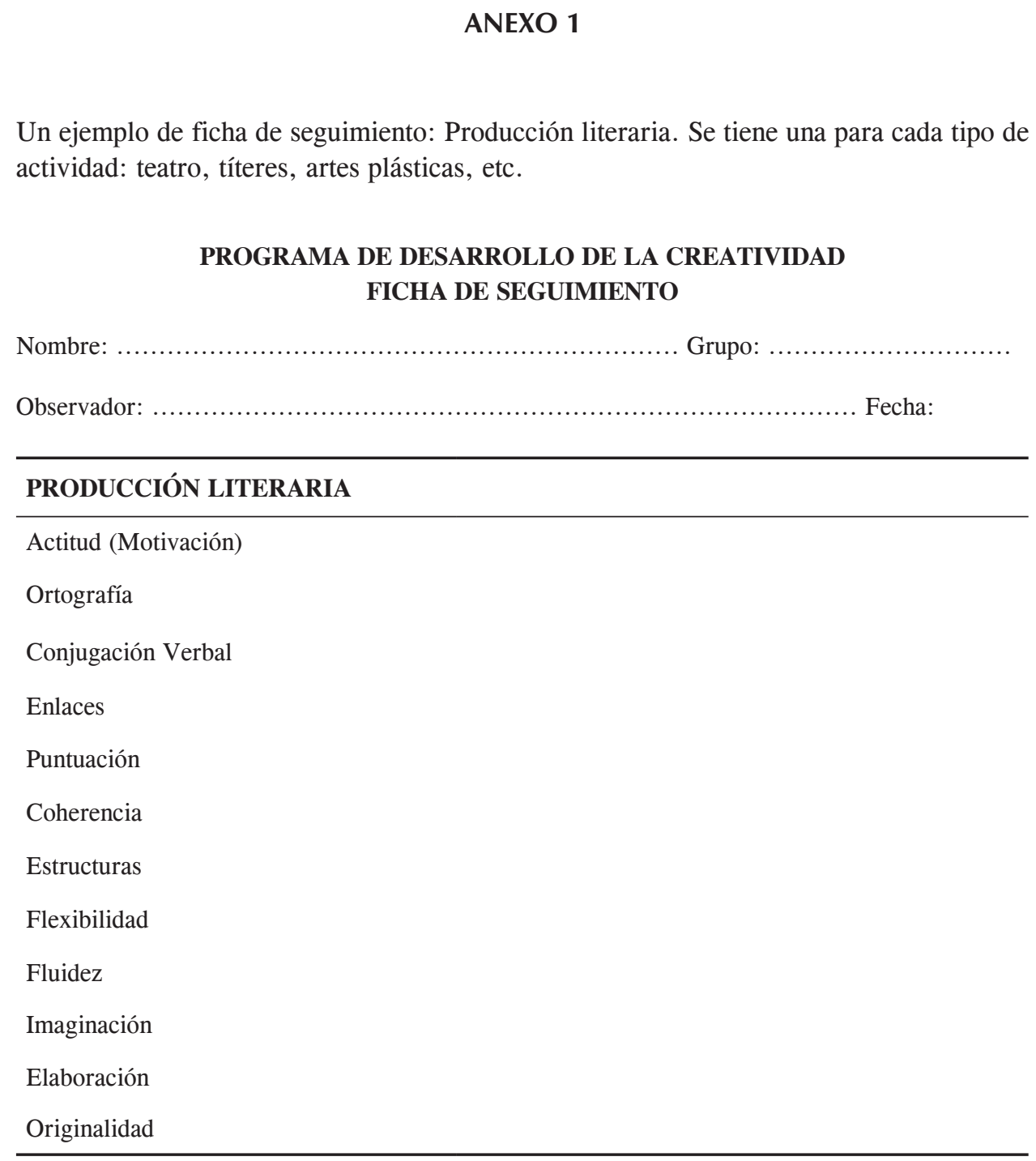




\section{ANEXO 2 \\ RESEÑA DE EVALUACIÓN DE LOS NIÑOS EN EL TALLER}

Los niños y niñas que participan en el Taller de Creatividad de la Unidad de Desarrollo de la Creatividad previamente son evaluados con una prueba que consta de lectura, comprensión de lectura, creatividad grafico-plástica, creatividad en producción de textos. En el antes y durante la evaluación se observa las habilidades comunicativas, de desempeño social, estado emocional de los participantes. Todo ello se realiza con la finalidad de obtener una línea base y observar el proceso de desarrollo de éstas áreas en el transcurso de las sesiones.

Luego de la evaluación, todos los niños y niñas participan de las sesiones del Taller, reiteramos que la evaluación es para conocer las zonas de desarrollo de los niños, sus zonas potenciales; así como sus desempeños sociales y comunicacionales.

En caso haya niños o niñas que se encuentren con dificultades a nivel emocional o afectivas, el taller cumple la función terapéutica de mejorar la percepción que ellos tengan de sí mismos, desarrolla sus habilidades sociales, mejoran sus niveles comunicativos, desarrollan sus niveles afectivos y expresivos.

Por esta razón el Taller está diseñado con diferentes actividades que propician desarrollo personal, es decir a niveles cognitivo, afectivo y volitivo.

Al final del taller, los niños y niñas se encuentran más desenvueltos, más alegres, más satisfechos consigo mismos, desinhibidos, mejoran su expresión corporal, su expresión verbal, tienen mayor apertura a la crítica, poseen mayores recursos para encontrar mejores posibilidades a la solución de problemas, sobre todo desarrollan su creatividad para producir literariamente y plásticamente. Además tiene otras perspectivas para analizar las situaciones y hechos de su entorno social, se vuelven más críticos.

Además mejoran la expresión escrita, la lectura y sus niveles de comprensión.

En una palabra los niños "sufren" un cambio integral, evolucionan; unos desarrollan aquello que estuvo bloqueado o con déficit, otros potencian lo desarrollado. Existe a todo nivel una mejora personal que hace que los niños y niñas mejoren su autoestima, sean más productivos y, sobre todo, más creativos.

\section{ORGANIZACIÓN DEL TALLER DE CREATIVIDAD Y LITERATURA}

\section{Transformándonos}
a) Técnica
: Dinámica de animación
b) Objetivos
: Animar y estimular la imaginación
c) Materiales
: Alfombra, equipo de sonido y CD musical
c) Procedimiento : Los niños se ubican descalzos sobre la alfombra, el director de
la actividad comunica que el juego consistirá en movilizarse 
representando el animal que se les diga. La actividad se acompaña con un fondo musical, el director irá diciendo: Son peces que nadan en el mar...Ahora son reptiles que caminan por la tierra... Se han convertido en felinos que andan por la selva...(tras varias representaciones): Ahora son aves, las aves vuelan por el cielo... finalmente se posan en sus nidos (los niños se sientan sobre la alfombra formando un ruedo).

d) Tiempo : 10 minutos.

\section{Saludos y presentación}

a) Objetivos : Practicar habilidades sociales básicas y propiciar el autoconocimiento

b) Procedimiento : Tras la primera actividad, el director inicia la ronda de presentaciones saludando y dando su nombre, los demás deben responder al saludo; el director además dirá en pocas palabras cómo es él. Todos los participantes procederán del mismo modo.

c) Tiempo : 10 minutos.

\section{Lectura literaria}

a) Actividad : Lectura participativa.

b) Objetivos : Animar a la lectura y desarrollar la habilidad lectora oral.

Propiciar un proceso de autoconocimiento y expresión de sí mismos.

c) Materiales : Fotocopias de la canción No soy de aquí (adaptación) de F. Cabral o de la canción Mi niñez (adaptación) de J. M. Serrat

d) Procedimiento : El director de la actividad pide que un niño voluntariamente inicie la lectura del texto en voz alta, luego se indica a otro que continúe y así sucesivamente hasta culminar el texto. Cuando se presenta un error o dificultad en la lectura oral el facilitador inmediatamente interviene para hacer la corrección correspondiente.

e) Tiempo : 10 minutos

\section{Comprensión lectora}
a) Técnica
: Conversatorio
b) Objetivos
: Comprensión literal, inferencial y valorativa del texto leído.
c) Procedimiento : El facilitador promueve el análisis y comentarios por parte de los niños mediante preguntas, a la vez absuelve las preguntas de los niños y busca la reflexión acerca del texto.
d) Tiempo
: 15 minutos 
5. "Yo soy así"
a) Técnica : Frases incompletas
b) Objetivos : Realizar un ejercicio de autoconocimiento y expresión de sí mismos
c) Materiales : Fotocopias de ficha con frases incompletas, lápices y borradores.
d) Procedimiento : Se da instrucciones a los niños acerca del completamiento de las frases incompletas, ellos deben llenar toda la ficha, aunque excepcionalmente pueden no completar algunas frases.
e) Tiempo : 20 minutos

\section{Un poema para mí mismo}
a) Técnica
: Versificación libre
b) Objetivos
: Producir poemas sobre sí mismos y fortalecer la autoestima
c) Materiales
: Ficha de frases incompletas llenada, hojas rayadas, lápices y borradores.
d) Procedimiento : El director escribe en la pizarra algunas frases completadas sobre sí mismo y, pidiendo aportes y sugerencias al grupo, las va transformando en versos; de este modo los niños tienen un ejemplo de como proceder para construir poemas sobre sí mismos usando la ficha completada. Cada uno debe escribir un poema, los facilitadores brindarán la asesoría que los niños requieran. Finalmente, cada uno leerá para todos el poema que ha creado.

\section{* RESULTADOS}

(Algunos ejemplos):

\section{KIARA BUSTAMANTE ROSAS, 6 años}

\section{KIARA}

Soy tierna y alegre

como la flor del parque, soy una niña buena

como la mariposa de un árbol.

A mí me gusta colorear

$y$ dibujar y hacer cuentos.

$Y$ me voy a convertir en cisne

para nadar en el lago.

Me gusta el sabor de la galleta.

Cuando sea grande voy a ser

doctora para curar niños. 
Investigación-acción: Reseña y aportes del Taller de Creatividad del Consultorio Psicológico de la UNMSM

CELESTINA CARCAMO MALLQUI, 12 años

\section{VIDA}

Yo era tan solo una pequeña niña con dos luceritos en mi cara, una boquita pequeña y muy refinada.

Encontré un perro que era muy tímido y callado, me abrazaba con ternura en la fría primavera.

Entré a un mundo imaginario de cosas fantasiosas jugando con muchas osas me volví un lindo canario.

Pensando en un cielo azul me puse a volar cometas, me apuntaron con una escopeta

y soñé con una trompeta

Desperté de un lindo sueño y todo seguía igual, creí que era una fantasía la cual yo esperaría. 


\begin{abstract}
ANEXO 3

\section{EVALUACIÓN DE VOLUNTARIOS}

Los voluntarios son estudiantes de la Facultad de Psicología de la UNMSM. Son evaluados primero mediante entrevista individual y luego mediante un taller grupal donde los aspirantes participan en actividades lúdicas, plásticas, literarias y teatrales. Se valoran sus actitudes, sus cualidades creativas, su dominio técnico de la redacción, sus conocimientos en general; así como su desempeño social, el manejo de sus emociones, la flexibilidad y la perseverancia. Asimismo se desea que el voluntario sea una persona proactiva, responsable y comprometida; que se implique y disfrute de las actividades, que tenga una buena disposición para trabajar con niños, que tenga mucha paciencia y optimismo, con capacidad para dirigir grupos y transmitir alegría, y comprometida con su propio desarrollo personal y profesional.
\end{abstract}

La UDECREA, con relación a los voluntarios, constituye un espacio que contribuye a su formación profesional. Los estudiantes y egresados que han participado en el voluntariado no solo han adquirido conocimientos acerca de la creatividad, sino que también se han tornado más creativos y flexibles; son personas que han ganado experiencia y han adquirido mayores recursos para el ejercicio profesional.

La participación de los voluntarios en los talleres permite brindar un asesoramiento más personalizado a los niños y niñas, permite que se pueda atender mejor sus necesidades, pues el trabajo de equipo posibilita todo ello. Además contribuye a que los niveles de atención y concentración de los niños, en general, mejoren, que desarrollen sus niveles de comprensión lectora y logren un mejor dominio de la expresión escrita, que se sientan importantes pues se le brinda a cada uno de los niños una atención especial, con calidez y buen ánimo y mucho ingrediente de afecto.

Los voluntarios, además, aportan ideas para el desarrollo de los talleres.

Los voluntarios aprenden a trabajar y tratar con los niños, a comprenderlos, a ayudarlos y orientarlos. Asimismo mejoran sus niveles de observación; aprenden sobre la creatividad, sus niveles e indicadores; también sobre la comprensión lectora y a expresarse creativamente mediante la escritura, a usar diversas técnicas plásticas, así como a manejar actividades lúdicas, teatrales, con títeres, y a aplicar todos estos recursos en el trabajo con niños para promover su desarrollo creativo. Aprenden a realizar la evaluación en la evolución de los niños a quienes asesoran, por tanto desarrollan sus niveles de observación, lo mismo que recursos didácticos para el trabajo personalizado con los niños. Asimismo aprenden a redactar informes evaluando el proceso de intervención del Taller de Creatividad y Literatura en las mejoras cognitivas, creativas y personales del niño.

Igualmente, se ha observado cambios de actitudes de los voluntarios, desarrollo de sus intereses para con la profesión, también desarrollo personal pues logran ser más expresivos, comunicativos, con mejores habilidades sociales, más alegres y comprometidos con el trabajo que se realiza en la UDECREA del Consultorio Psicológico de San Marcos. 


\section{TALLER PARA ASPIRANTES AL VOLUNTARIADO EN LA UDECREA}

La Unidad de Desarrollo de la Creatividad del COPSI-UNMSM realiza un Taller para aspirantes al voluntariado en la UDECREA dirigido a estudiantes de la Facultad de Psicología de la UNMSM. En el taller se ejecutan actividades lúdicas, plásticas, literarias y teatrales. El taller permite identificar las habilidades y actitudes de los aspirantes con relación a las áreas de trabajo de la UDECREA, así como las cualidades personales relevantes para formar parte del equipo de la UDECREA. El objetivo central del taller es seleccionar nuevos voluntarios, evaluando el desempeño de los aspirantes en actividades lúdicas y en habilidades sociales, destacando las cualidades personales relevantes para formar parte del equipo de trabajo. Se trata de una evaluación en la actividad, con un programa de trabajo a desarrollar. 


\section{ANEXO 4 \\ ¿CÓMO SE ORGANIZA UNA SESIÓN DE TRABAJO?}

Cuando se prepara un taller, el equipo de la UDECREA planifica toda la secuencia de sesiones que comprenderá el taller, y si bien cada sesión funcionará independientemente, a la vez todas las sesiones estarán concatenadas, constituyendo una secuencia de menor a mayor complejidad. El equipo decide qué temas se trabajarán a través del taller y procede a planificar sesión por sesión. El taller comprende determinadas áreas de trabajo y en general todas las sesiones tendrán una estructura similar. En cada sesión habrá actividades lúdicas, plásticas, literarias y teatrales, pero dichas actividades siempre serán diferentes. También habrá algunas actividades para promover el desarrollo de las habilidades sociales y la autoestima, aunque dicha promoción a la vez estará comprendida en todas las áreas.

Para cada sesión se seleccionan juegos, técnicas artísticas, lecturas, recursos literarios, ejercicios, etc. La creación literaria es el eje, asimismo en cada sesión hay temas específicos; entonces en función de la creación literaria y de los temas específicos se hace la selección mencionada y se organizan todas las actividades. Cada actividad tiene objetivos específicos y a la vez sirve al eje. Asimismo todas las actividades estarán articuladas entre sí, de modo que permitan generar todo un proceso creativo.

Con antelación a la ejecución de la sesión, el equipo hace los ajustes necesarios, revisa las actividades, ensaya los juegos y también los ejercicios teatrales o de títeres, asimismo ensaya las obras teatrales o de títeres que va a presentar (si están programadas), practica las técnicas plásticas, ejercita los recursos literarios, coordina tareas y funciones y prepara materiales.

\section{UNA SESIÓN (EJEMPLO)}

La sesión de trabajo es organizada integralmente, es decir todas las áreas cumplen un fin, tiene un objetivo y se encuentran articuladas. Primero se selecciona el recurso, ya sea en poesía o en cuento, que se va a trabajar en la sesión. Por ejemplo, si los niños van a conocer las partes de un cuento, entonces desde el inicio se selecciona una dinámica de animación que tenga que ver con ello. La dinámica sería "Había una vez..." donde el grupo forma un ruedo, cada niño está dentro de un círculo dibujado en el piso, y cada participante escoge su personaje favorito de cuento, luego el que dirige dice "Había una vez..." y va mencionando los personajes que los niños han escogido, los niños van saliendo según son llamados y siguen al que dirige hasta que éste dice "y colorín colorado el cuento ha terminado" entonces los niños y facilitadores vuelven a los círculos, habrá uno que se quede fuera y éste es quien continúa el juego. Luego en el ruedo los niños saludan y se presentan, los demás niños y facilitadores le responden el saludo, se trabaja ello con el fin de que los niños aprendan a desenvolverse socialmente. Posteriormente, se presenta a los niños un conjunto de pequeños cuentos escritos en papelógrafo, en ellos se distinguen claramente las partes de un cuento (estructura) y todos estos pequeños cuentos están divididos en igual número de párrafos; dichos párrafos son intercambiables, es decir se pueden combinar los de un cuento con los de otro manteniendo la estructura, dando lugar a resultados graciosos. Los niños leen 
los pequeños cuentos y también combinan lúdicamente sus párrafos. Luego se trabaja una técnica plástica, donde ellos puedan elaborar un personaje; primero el facilitador-guía realiza el trabajo compartiéndolo colectivamente y después los niños elaboran con la técnica individualmente. Seguido a la producción plástica, el facilitador-guía dirige la producción colectiva de un cuento teniendo como referencia los cuentos leídos; se busca la participación de todos los niños, que expresen sus ideas, las que finalmente verán plasmadas en el texto escrito en la pizarra. Se hace énfasis en los contenidos de cada parte, para que luego los niños individualmente construyan sus cuentos inspirados en el personaje que han elaborado en la actividad plástica. En la producción individual los niños reciben asesoría; a aquellos que necesitan más ayuda se les hace un acompañamiento de inicio a fin de su producción, y en general se va realizando el seguimiento por parte de todos los facilitadores hacia todos los niños. Para finalizar la producción escrita, se trabaja con cada niño la mejora del texto, que consiste en ver si hay la coherencia lineal y global del texto, la adecuada construcción gramatical, la ortografía. Finalmente se trabaja el área de teatro de títeres, donde los niños, guiados por el facilitador, realizan ejercicios de expresión corporal, proyección de la voz, diferentes voces para el personaje-títere. Luego se forman equipos para que elaboren un pequeño guión, asesorados por un faciitador, lo ensayan y realizan la puesta en escena en el teatrín. En la elaboración del guión, nuevamente se enfatiza las partes del cuento para que elaboren la historia que pondrán en escena. Cada grupo de niños saldrá a representar su guión en el teatrín.

\section{¿CÓMO SE PREPARA LA ÚLTIMA SESIÓN?}

La última sesión se prepara buscando cohesionar aun más el grupo de participantes y alimentar la autoestima de cada uno. En dicha sesión se plantea un proyecto editorial con los textos seleccionados de cada uno de los niños, ellos deben proponer el título que llevará el libro del cual serán autores. Finalmente ensayarán las obras teatrales o de títeres que produjeron por equipos en el taller y que presentarán en la clausura.

\section{¿CÓMO ELABORAMOS EL TEXTO QUE SE DA AL FINAL A LOS NIÑOS?}

Se tipean todos los poemas y cuentos preseleccionados de los niños, luego se seleccionan los mejores de cada uno, finalmente se decide cuáles son los textos prescindibles y quedan los de mayor calidad o los más logrados. De cada niño habrá por lo menos un texto. Todos los textos llevan el nombre del autor correspondiente y la edad del mismo. Asimismo se hace una revisión general de los textos y se corrigen los errores que hayan quedado.

Los niños conocen el proyecto editorial y proponen alternativas para darle título al libro con sus textos; se elige la alternativa más adecuada. Por otro lado se selecciona entre los trabajos plásticos de los niños uno de los más representativos y con dicho trabajo plástico se compone la portada del libro. En el libro se incluye una sección con algunos de los cuentos y poemas de autores reconocidos que fueron leídos en el taller. Asimismo se incluye una sección con artículos (elaborados para el libro) sobre el desarrollo de la creatividad en los niños. Por último se redacta una introducción. 
Talleres y productos realizados en el COPSI - UNMSM

\begin{tabular}{|c|c|c|c|c|}
\hline $\mathbf{N}^{\mathbf{o}}$ & Año & Periodo & Talleres & Textos elaborados (publicaciones) \\
\hline 1 & 2004 & Enero- marzo & $\begin{array}{c}\text { Taller de Creatividad } \\
\text { y Literatura }\end{array}$ & Los traviesos de la literatura \\
\hline 2 & 2005 & Enero- marzo & $\begin{array}{c}\text { Taller de Creatividad } \\
\text { y Literatura }\end{array}$ & El cofre de los cuentos \\
\hline 3 & 2005 & Abril - julio & $\begin{array}{c}\text { Taller de Creatividad } \\
\text { y Literatura }\end{array}$ & El bosque de los cuentos mágicos \\
\hline 4 & 2005 & $\begin{array}{l}\text { Agosto- } \\
\text { noviembre }\end{array}$ & $\begin{array}{c}\text { Taller de Creatividad } \\
\text { y Literatura }\end{array}$ & De los niños para el Perú \\
\hline 5 & 2006 & Enero- marzo & $\begin{array}{c}\text { Taller de Creatividad } \\
\text { y Literatura }\end{array}$ & Poemas y cuentos de las estrellas \\
\hline 6 & 2006 & Abril - julio & $\begin{array}{c}\text { Taller de Creatividad } \\
\text { y Literatura }\end{array}$ & El libro de los chicos alegres \\
\hline 7 & 2006 & $\begin{array}{l}\text { Agosto- } \\
\text { noviembre }\end{array}$ & $\begin{array}{c}\text { Taller de Creatividad } \\
\text { y Literatura }\end{array}$ & Los sueños de los niños \\
\hline 8 & 2007 & Enero- marzo & $\begin{array}{c}\text { Taller de Creatividad } \\
\text { y Literatura }\end{array}$ & Arco iris de creaciones \\
\hline 9 & 2007 & Abril - julio & $\begin{array}{c}\text { Taller de Creatividad } \\
\text { y Literatura }\end{array}$ & Un árbol de cuentos y poemas \\
\hline 10 & 2007 & $\begin{array}{l}\text { Agosto- } \\
\text { noviembre }\end{array}$ & $\begin{array}{c}\text { Taller de Creatividad } \\
\text { y Literatura }\end{array}$ & $\begin{array}{c}\text { Los niños enamorados de la } \\
\text { creación }\end{array}$ \\
\hline 11 & 2008 & Enero- marzo & $\begin{array}{c}\text { Taller de Creatividad } \\
\text { y Literatura }\end{array}$ & El viaje de la creatividad \\
\hline 12 & 2008 & Abril - julio & $\begin{array}{c}\text { Taller de Creatividad } \\
\text { y Literatura }\end{array}$ & En el universo de la imaginación \\
\hline 13 & 2008 & $\begin{array}{l}\text { Agosto- } \\
\text { noviembre }\end{array}$ & $\begin{array}{c}\text { Taller de Creatividad } \\
\text { y Literatura }\end{array}$ & Una aventura sin limites \\
\hline 14 & 2009 & Enero- marzo & $\begin{array}{c}\text { Taller de Creatividad } \\
\text { y Literatura }\end{array}$ & Un mar de sueños \\
\hline
\end{tabular}




\section{ANEXO 5}

¿Qué pasa con los padres y madres de los participantes en el Taller de Creatividad y Literatura del COPSI?

Es realmente increíble compartir la alegría y el entusiasmo de los padres y madres de los participantes en el Taller de Creatividad y Literatura del COPSI. Los padres y las madres de los participantes expresan sus deseos y sus sueños acerca de las potencialidades creativas de sus hijos e hijas. Los imaginan pintando, escribiendo, recitando, actuando, etc. Saben o intuyen de manera práctica que los aprendizajes que realizan sus hijos e hijas son de mucha utilidad y que aprenden a ser mejores personas.

Al conversar con los padres y las madres, tengo la impresión de que son los mejores propagandistas del Taller de Creatividad y Literatura del COPSI. Para comenzar salen con ganas de volver, de traer nuevamente a sus hijos e hijas, para que sigan aprovechando de las ventajas que brinda el aprendizaje de la creatividad personal. Recomiendan a sus vecinos, amigos y familiares sobre la base de su experiencia personal y comunican en todo momento su satisfacción por lo bueno y positivo que es la experiencia. Destacan simplemente que las conductas personales de sus hijos e hijas han mejorado tanto en la familia como en la escuela. Así, las personas creativas tienen mejores desempeños personales, mayor entusiasmo por la vida y mayor capacidad de compartir solidariamente experiencias personales.

\section{¿CÓMO EDUCAR HIJOS FELICES?}

En el presente ensayo psicopedagógico tiene el propósito de alcanzar a las madres y padres de familia un Decálogo del amor* para mejorar la dinámica familiar y para educar hijos felices, mediante principios orientadores de la conducta personal que invitan a la reflexión y a la renovación personal.

En tal sentido, el Decálogo del amor pretende ser, en términos prácticos, un instrumento útil para dar sentido positivo y constructivo a la dinámica de relación familiar. Tiene un contenido orientador que es posible ponerlo en práctica para mejorar la calidad de las relaciones familiares.

Ahora bien, ¿cómo entender prácticamente los principios orientadores de la conducta personal del Decálogo del amor?

En primer lugar, los principios orientadores de la conducta personal son útiles porque funcionan como una especie de mandamientos para orientar la tarea formativa de la familia con relación a los hijos. Se trata de orientaciones formativas para educar hijos felices, poniendo en práctica sus sugerencias en la vida cotidiana.

En segundo lugar, los principios orientadores de la conducta personal son útiles porque concentran consejos prácticos para mejorar las relaciones de pareja y la educación de los hijos. Son orientaciones prácticas para la formación integral de la personalidad y para mejorar la calidad de vida de la familia.

\footnotetext{
* Decálogo del amor es el resultado de una re-CREACIÓN. Se trata de una re-elaboración creativa que uniformiza la redacción, precisando y mejorando la orientación formativa. Adaptado de http://patolina22.spaces.live.com
} 


\section{DECÁLOGO DEL AMOR}

1. Serás fuente de amor vital. El amor es fuente de vida y da sentido a la convivencia humana. Mediante el amor la vida se mantiene a través de las generaciones y nos hace vivir aún después de la muerte.

2. Practicarás el arte de amar. Los pasos necesarios para aprender todo arte son: dominio de la teoría, dominio de la practica y considerarlo como algo fundamental en tu vida.

3. Desarrollarás tus zonas mágicas. No olvidarás la dimensión espiritual del amor, que es como un manantial de creatividad amorosa. El amor es generativo en sus expresiones esenciales y en sus manifestaciones solidarias, por eso la gente dice: "Dios es Amor".

4. Guiarás tu corazón con la razón. El amor exige inteligencia intuitiva y sentimientos razonados. El amor ciego nunca fue duradero ni verdadero. Para amar bien se requiere de un corazón bien informado.

5. Amarás guiado por un sentido de reciprocidad. El amor exige una madurez afectiva, por la cual el deseo de posesión se complementa con el deseo de donación a la persona amada.

6. Amarás con responsabilidad. El amor exige responsabilidad, por eso vulgarmente dicen que "el amor esclaviza". Sin embargo, el amor auténtico personaliza (somos lo que somos por los amores que tenemos), es fuente de gozo existencial (gratifica) y de alegría vital (forja felicidad).

7. Serás expresión viva de la solidaridad. No confundirás amor con egoísmo. El egoísmo usa de las personas como si fueran "objetos o cosas", esclavizándolas y manipulándolas. El amor solo piensa en el bien y en la realización del amigo y de la persona amada.

8. Descubrirás que el amor humano no es juego. El auténtico amor no se reduce al juego amoroso, sobre todo al juego vulgar que despersonaliza y genera tensiones negativas en el corazón. El juego amoroso en el amor auténtico implica tensión creativa y motivadora.

9. Aprenderás a convivir amorosamente. El amor nos exige salir de nosotros mismos y nos invita a practicar del altruismo. El amor construye convivencia fraterna y nos impulsa a crear condiciones propicias para la donación solidaria.

10. Superarás las dificultades con amor. El amor es clave para superar las dificultades, pues con amor y por amor se siente más intensa y plenamente la vida. No olvides que la "alegría de vivir" y la "alegría de aprender" son fuerzas impresionantes para alcanzar objetivos maravillosos y metas extraordinarias. 